\title{
Ectopic adrenal tissue in the kidney: A systematic review
}

\author{
Davide De Marchi ${ }^{1^{*}}$, Alessandro Tafuri ${ }^{2-4^{*}}$, Guglielmo Mantica ${ }^{5}$, Aliasger Shakir ${ }^{6}$, Federico Scarfò ${ }^{7}$, \\ Giovanni Passaretti ${ }^{1}$, Salvatore Smelzo ${ }^{1}$, Silvia Proietti ${ }^{1}$, Lorenzo Rigatti ${ }^{1}$, Roberta Luciano ${ }^{7}$, \\ Alessandro Antonelli ${ }^{3}$, Vincenzo Pagliarulo ${ }^{2}$, Rosario Leonardi ${ }^{1}$, Guido Giusti ${ }^{1}$, Franco Gaboardi ${ }^{1}$ \\ ${ }^{1}$ Department of Urology, San Raffaele Hospital, Milan, Italy; \\ ${ }^{2}$ Department of Urology, "Vito Fazzi" Hospital, Lecce, Italy; \\ ${ }^{3}$ Department of Urology, University of Verona, Azienda Ospedaliera Universitaria Integrata Verona, Verona, Italy; \\ ${ }^{4}$ Department of Neuroscience, Imaging and Clinical Sciences, University "G. d'Annunzio" of Chieti-Pescara, Chieti, Italy; \\ ${ }^{5}$ Department of Urology, University of Genova, Ospedale San Martino, Genova, Italy; \\ ${ }^{6}$ USC Institute of Urology, Catherine and Joseph Aresty Department of Urology, Keck School of Medicine, University of Southern \\ California (USC), Los Angeles, CA, USA; \\ ${ }^{7}$ Department of Pathology, San Raffaele Hospital, Milan, Italy. \\ ${ }^{*}$ Equal contribution.
}

\begin{abstract}
Summary Introduction: Ectopic adrenal tissue in the kidney, including "Ectopic adrenal tissue" and "Adrenal-renal fusion", is a rare event with a specific behavior which may be difficult to distinguish clinically from renal neoplasms. We performed a systematic review on ectopic adrenal tissue variants reported in the literature underlining its clinical aspects.

Methods: Manuscripts which presented a case report or case series of ectopic adrenal tissue in the kidney were included even if published in original articles, reviews, or letters to the editor. A specific search on SCOPUS ${ }^{\circledR}$, PubMed $^{\circledR}$, and Web of Science ${ }^{\circledR}$ database was performed. Only English language papers published in a period ranging between August 1991 and April 2020 were considered. Additionally, a case we had at our institution is described, and its characteristics are included. Data on clinical presentation, type of adrenal anomaly, location, anatomopathological and immune-histotype characteristics were collected.

Results: We identified 888 manuscripts. Among these 29 were included in this systematic review. Overall, 39 patients with renal adrenal fusion or adrenal ectopia were considered. In most cases, the diagnosis was made incidentally, or following investigation for flank pain, abdominal pain, or endocrinological disorders. CT scan frequently identified a solid vascularized lesion that was difficult to distinguish from renal neoplasm. Adrenal fusion was mostly located at the level of the upper pole. Adrenal rest was found in the renal parenchyma, renal hilum, or retroperitoneum in close proximity to the renal peduncle. Often these ectopic adrenal tissue lesions follow a benign behavior and can be classified as functioning or non-functioning adenomas. Rarely, they may experience neoplastic degeneration. The most frequently positive markers were inhibin, vimentin, melan-A, synaptophysin and anti-p450 scc.

Conclusions: Ectopic adrenal tissue in the kidney is a rare event with specific clinical characteristics that need to be identified in order to arrive at a correct diagnosis and carry out appropriate treatment management.
\end{abstract}

KEY WORDS: Intrarenal adrenal tissue; Ectopic adrenal tissue; Renal-adrenal fusion; Adrenal rest; Incidental renal masses; Renal cancer; Small renal mass.

Submitted 19 September 2021; Accepted 23 September 2021

\section{INTRODUCTION}

Renal cancer represents 3\% of all neoplasms in western Countries. During the last few years, its incidence increased by $2 \%$ due to an increased amount of incidental radiological diagnosis, especially for small renal masses ( $<4 \mathrm{~cm}$ of diameter) $(1,2)$, for which nephron sparing surgery is the treatment of choice (3). However, these small lesions can behave biologically different from other renal masses. It is estimated that $20-30 \%$ of small renal masses are benign and active surveillance is an acceptable tool that can be used to avoid the surgery and its related risks in this cohort of patients (2-4). The presence of ectopic adrenal tissue in the kidney, while benign, is a rare event that needs to be identified and distinguished from renal cancer. This condition can be divided into two entities based on the pathophysiological origin.

First, "Ectopic adrenal tissue" or "adrenal rest", initially described by Morgagni in 1740, is a congenital anomaly due to the migration, to other organs, of fragments of the primitive adrenal gland, and can be classified as "true" or "accessory" ectopy depending on the migration of the whole or part of the gland, respectively $(5,6)$.

Second, "Adrenal-renal fusion", first described by Rokitansky in 1855 (7), could be divided into a "congenital" form when it is caused by failure of the retroperitoneal mesenchymal cells to stimulate adrenal capsule formation, or "acquired" form when it is a consequence of inflammation of the perirenal fat. Consequently the adrenal gland becoming fused with the renal parenchyma, and become anatomically indivisible from the kidney (8).

Most ectopic adrenal tissue is located along the migration path of the urogenital system but it could be present also at the level of celiac axis, broad ligament, spinal cord and other retroperitoneal parenchymatous organs (9). Ectopic adrenal tissue can be present in $50 \%$ of newborns, usually regressing and persisting in only $1 \%$ of the adult population (10). It is not a rare condition and can manifest clinically as endocrine abnormalities due to secretory activity, mass effect or neoplastic transformations. Additionally, due to the location where these lesions can arise, adrenal rest becomes part of the differential diagno-

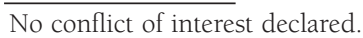


sis along with renal cell carcinoma and for this reason it must be correctly diagnosed (11). Here, we report a systematic review of the literature on ectopic adrenal tissue while underlining its main clinical aspects.

\section{Methods}

We performed a systematic review limited to case reports, case series and all formats reporting a case description on our specific topic. The purpose of this literature review is to describe the salient features of adrenal ectopia in order to assist the differential diagnosis process with renal neoplasms. For this reason, we considered only adrenal ectopias located at the renal level or in the retroperitoneum in close proximity to the renal pelvis in the study. A specific search on SCOPUS ${ }^{\circledR}$, PubMed $^{\circledR}$, and WEB OF SCIENCE ${ }^{\circledR}$ database was performed including "[(intrarenal adrenal tissue) OR (ectopic adrenal tissue)] OR [(renal -

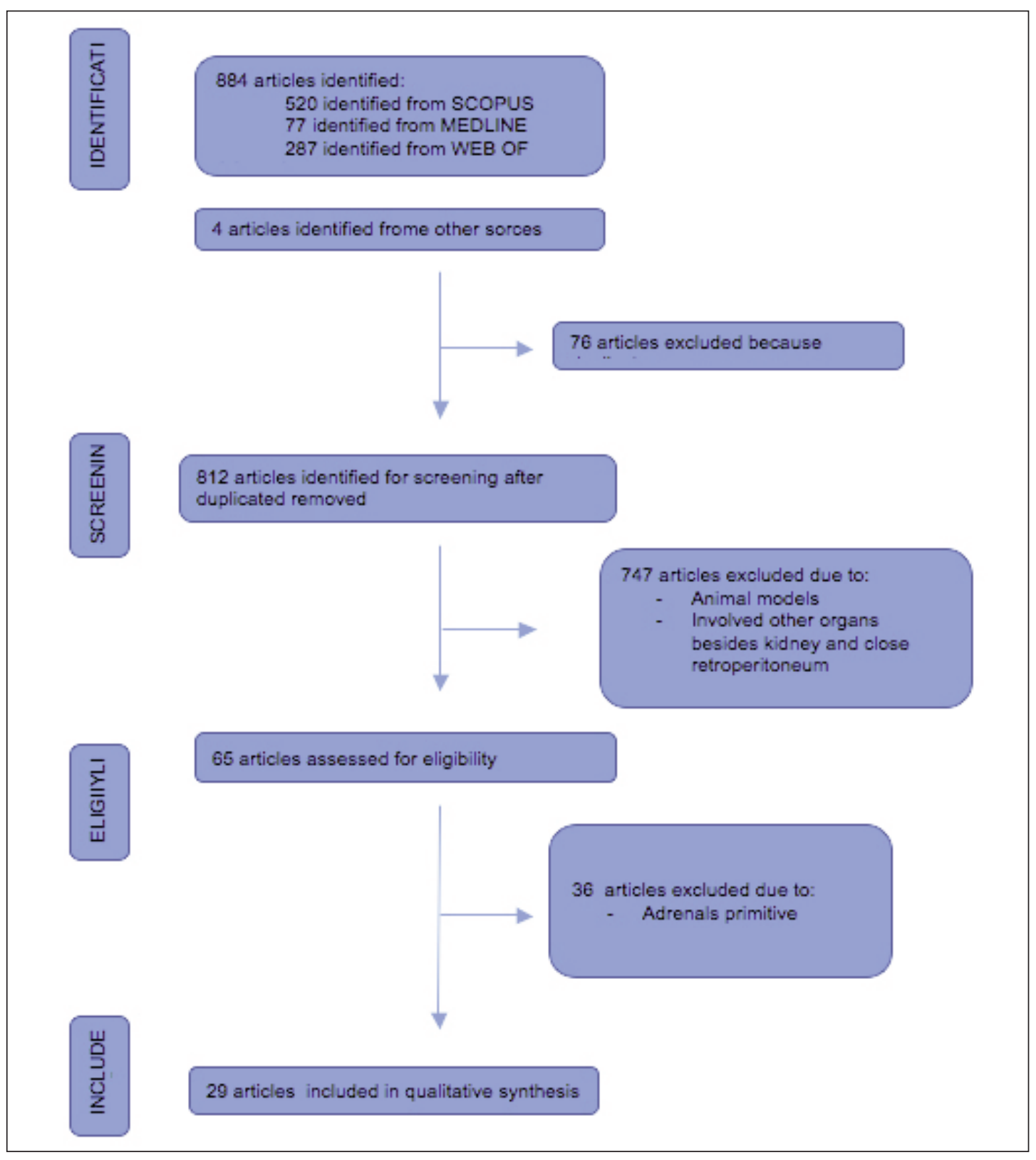

Figure 1.

In November 2017, a 66 year-old man with a previous history of diabetes mellitus, hypertension, and benign prostatic hyperplasia came to our Institution.

Due a single episode of hyperpyrexia associated with left flank pain, he performed an abdomen ultrasound with incidental finding of a left renal mass, and a following abdomen CT scan which confirmed the presence of an exophytic solid lesion of $10 \times 14 \mathrm{~mm}$, in the middle lateral margin of the left kidney (R.E.N.A.L. score 6A; P.A.D.U.A. 7 A), (Figure 2 A-B-C-D).

Both adrenal glands had regular morphology, size and location. Complete blood count, creatinine, urine analysis values were all within normal limits.

Given the small size of the neoformation, active sunveillance of the neoformation was proposed to the patient but he preferred to remove the mass, and robot assisted left partial nephrectomy was performed in January 2018. A clampless enucleoresection was performed with a continuous suture on the resection bed by sliding suture technique with Hem-0-Lok.

The post-operative period was regular and uncomplicated. The patient was discharged after three days. The definitive anatomopathological report reports "ectopic adrenal gland with renal tissue where occasional tubular thyroidization and minimal interstitial chromic nephritis" (Figure 3 A-B). The follow up was negative. Ultrasound of the abdomen and blood test with kidney function evaluation was negative.

Box 1. Case report. 
Table 1.

Clinical and pathological characteristics of adrenal ectopias findings in the included studies.

\begin{tabular}{|c|c|c|c|c|c|c|}
\hline Author & Type of article & $\mathrm{N}^{\circ}$ of case & Clinical Presentations & Adrenal abnormalities & AP report & Markers \\
\hline Goren et al. 1991 (14) & Case report & 1 case & Left lumbar pain & Adrenal rest & Ectopic adrenocortical adenoma & NS \\
\hline Chin et al. 1994 (6) & Case report & 1 case & Incidental finding in patient with kidney neoplasia & True heterotopia & ectopic adrenocortical adenoma & Anti-P450 scc+ \\
\hline Colberg et al. 1998 (15) & Case report & 1 case & abdominal pain and weight loss & Adrenal renal fusion & Adrenocortical adenoma & Pan cytokeratin - cytokeratin 7 - \\
\hline Ayala et al. 2000 (16) & Case report & 1 case & Cushing's syndrome & Adrenal rest & Ectopic adrenocortical adenoma & NS \\
\hline Souverijns et al. 2000 (17) & Case report & 1 case & Hypertension & Adrenal rest & Ectopic adrenocortical adenoma & Vimentin + \\
\hline Szumera et al. 2003 (11) & Case report & 1 case & NS & Adrenal rest & Ectopic adrenocortical adenoma & $\begin{array}{l}\text { Vimentin + synaptophysin } \\
\text { + cytokeratin- EMA- }\end{array}$ \\
\hline Fan et al. 2004 (18) & Case report & 1 case & Incidental findings in patients with metabolic syndrome & Adrenal renal fusion & Atrophic adrenal gland and renal cyst & NS \\
\hline Hsu et al. 2005 (19) & Case report & 1 case & Incidental findings in Patient with kidney neoplasia & Adrenal rest & Ectopic adrenocortical adenoma & NS \\
\hline $\begin{array}{l}\text { Claahsen-van der Grinten } \\
\text { et al. } 2008 \text { (20) }\end{array}$ & Case report & 1 case & $\begin{array}{l}\text { Abdominal pain in patient with congenital } \\
\text { adrenal hyperplasia }\end{array}$ & Adrenal rest & Adrenal rest tumour & $\begin{array}{l}\text { cytokeratins } 8 / 18 \text { + inhibin + } \\
\text { AE1/AE3 - epithelial membrane } \\
\text { antigen - CD68 - CD10 - placental-like } \\
\text { alkaline phosphatase - }\end{array}$ \\
\hline Baydar et al. 2008 (32) & Case series & 2 cases & Abdominal pain & Adrenal rest & $\begin{array}{l}\text { Ectopic adrenocortical adenoma } \\
\text { Eterotopic adrenal cortical tissue }\end{array}$ & $\begin{array}{c}\text { melan-A + inhibin + calretinin + } \\
\text { EMA- pancytokeratin - } \\
\text { melan-A + synaptophysin + } \\
\text { calretinin + EMA- CD68- } \\
\end{array}$ \\
\hline Lnder et al. 2009 (21) & Case report & 1 case & Incidental finding & Renal adrenal fusion & Adrenocortical adenoma & $\begin{array}{l}\text { MART-1 + MAK-6 + inhibin + } \\
\text { CD10 - hmb-45 - AE1/3 - SMA - }\end{array}$ \\
\hline Mahadevia et al. 2009 (22) & Case report & 1 case & Abdominal pain & Adrenal renal fusion & Adrenocortical adenoma & NS \\
\hline Ye et al. 2009 (12) & $\begin{array}{r}\text { Retrospective } \\
\text { cases series }\end{array}$ & 9 cases & & $\begin{array}{c}7 \text { adrenal rest } \\
2 \text { adrenal renal fusion }\end{array}$ & Ectopic adrenocortical adenoma & NS \\
\hline Louiset et al. 2010 (23) & Case report & 1 case & $\begin{array}{l}\text { ACTH-independent Cushing's } \\
\text { syndrome due to PPNAD }\end{array}$ & $\begin{array}{l}\text { Bilateral adrenocortical micronodular } \\
\text { hyperplasia and adrenal rest }\end{array}$ & $\begin{array}{l}\text { lar } \\
\text { Bilateral adrenocortical } \\
\text { micronodular hyperplasia and } \\
\text { ectopic adrenocortical adenoma }\end{array}$ & $\begin{array}{l}\text { 17- } \alpha \text { hydroxylase+ } \\
\text { 21- } \alpha \text { hydroxylase }{ }^{+}\end{array}$ \\
\hline Brčić et al. 2011 (15) & Case report & 1 case & Incidental finding & Adrenal rest & Ectopic adrenocortical adenoma & $\begin{array}{l}\text { HMB-45 + SMA + melan-A + } \\
\text { inhibin + Calretinin }{ }^{+} \\
\text {AE1/3 - CD10 - EMA- }\end{array}$ \\
\hline Cardinalli et al. 2012 (24) & Case report & 1 case & Incidental finding in Beckwith-Wiedemann syndrome & Adrenal rest & ectopic adrenocortical adenoma & NS \\
\hline Wang et al. 2012 (9) & Case report & 1 case & Cushing's syndrome & Adrenal rest & ectopic adrenocortical adenoma & NS \\
\hline Yokoyama et al. 2013 (25) & Case report & 1 case & Incidental finding & Adrenal rest & adrenocortical carcinoma & $\begin{array}{c}\text { P450c17 + SF-1 + DHEA-ST + } \\
\text { 3B-HSD + }\end{array}$ \\
\hline Tong et al. 2014 (26) & Case report & 1 case & Cushing's syndrome & Adrenal rest & Ectopic adrenocortical adenoma & Melan-A+ HSD3B2+ CYP17A1+ \\
\hline Godin et al. 2014 (27) & Case report & 1 case & Incidental finding & Adrenal rest & Oncocytic adrenocortical adenoma & NS \\
\hline Griffin et al. 2015 (28) & Case report & 1 case & Hypertension & Adrenal renal fusion & Multinodular adrenal cortical hyperplasia & NS \\
\hline Clair et al. 2015 (29) & Case report & 1 case & Abdominal pain & Adrenal renal fusion & Adrenocortical adenoma & NS \\
\hline Liu et al. 2016 (33) & Case report and review & 1 case & $\begin{array}{l}\text { Endocrinological Disorders: } \\
\text { Amenorrhea and virlization and } \\
\text { obstruction urinary output }\end{array}$ & Adrenal rest & Ectopic adrenocortical adenoma & $\begin{array}{c}\text { Vimentin + Inhibin } \alpha+ \\
\text { Melan-A + Synaptophysin + } \\
\text { NSE + CD56 + AE1/AE3 +/- } \\
\text { PAX 8 - S100 - Chromogranin A - }\end{array}$ \\
\hline Zhang et al. 2016 (10) & Case report and review & 1 case & Hypertension and bilateral limb weakness & Adrenal rest & Ectopic adrenocortical adenoma & $\begin{array}{c}\text { Synaptophysin + CD56 + } \\
\text { Vimentin + Ki-67 + (2\%) Inhibin } \alpha+ \\
\text { Calretinin + chromogranin A - CD117- } \\
\text { CD10 - CK7 - EMA - CK-pan - melan-A - }\end{array}$ \\
\hline Sappal et al. 2016 (34) & Case report and review & 1 case & Incidental finding & Adrenal rest & Ectopic adrenocortical adenoma & Melan-A+ PAX 8- \\
\hline Zhao et al. 2018 (30) & Case report & 1 case & Cushing's syndrome & Adrenal rest & $\begin{array}{l}\text { Adrenocortical adenoma with } \\
\text { myelolipoma metaplasia }\end{array}$ & NS \\
\hline Lee et al. 2018 (31) & Case report & 1 case & Back pain & Adrenal rest & Adrenocortical carcinoma & $\begin{array}{c}\text { Inhibin } \alpha+\text { Vimentin + } \\
\text { Synaptophysin + Melan A focal + }\end{array}$ \\
\hline Bamford et al. 2018 (8) & Case report & 1 case & Incidental finding in patient with bladder neoplasia & Adrenal renal fusion & & - \\
\hline \multirow[t]{3}{*}{ Luet al. 2018 (35) } & Case report and review & 1 case & ACTH-independent Cushing's syndrome & Adrenal rest & Ectopic adrenocortical adenoma & Inhibition + Melan-A + \\
\hline & & & & & & Synaptophysin + Vimentin + \\
\hline & & & & & & AE1/AE3 + HMB45 +/- CD34 + \\
\hline Current case & e report and systematic re & view 1 case & Incidental finding & Adrenal rest & Heterotopic adrenocortical adenoma & NS \\
\hline
\end{tabular}

adrenal fusion) OR (adrenal rest)] AND [(kidney cancer) OR (renal cancer) OR (renal cell carcinoma)]" MeSh terms. Only manuscripts in English language published in a period ranging between August 1991 and April 2020 were considered (Figure 1).

All the manuscripts which presented a case report or case series were included even if published in original articles, reviews, or letters to the editor.

Two authors (D.D.M.) and (G.M.) independently reviewed the literature using inclusion and exclusion criteria. All disagreements about eligibility were resolved by discussion with a third reviewer (A.T.) until consensus was reached. This study was performed using guidelines set out by Preferred Reporting Items for Systematic Reviews and metaanalysis (PRISMA) statement (12).

Additionally, a case at our institution is described, and its characteristics are included in the following evidence synthesis (Box 1, Tables 1-2). 
Table 2.

CT characteristics characteristics of adrenal ectopias findings in the included studies.

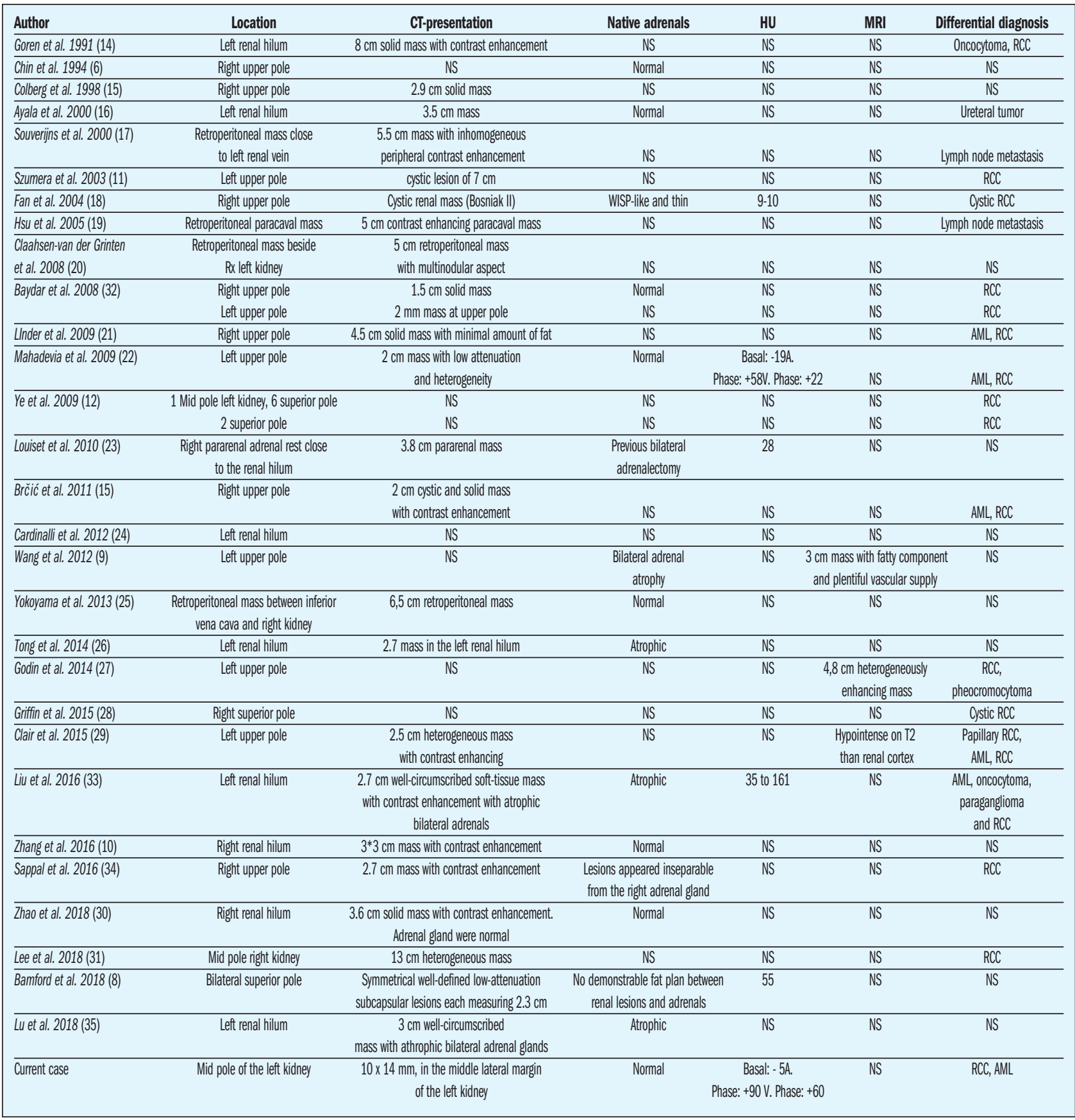

\section{RESULTS}

Our online search identified 888 publications. Sixty-five had all the inclusion criteria, and 29 were included in this systematic review. Among these, 22 were single case reports $(6,8,9,13-31), 2$ articles reported more than one case $(11,32), 4$ were literature reviews with case report (10, 33-35), and 1 article was a letter to the publisher including a case reports (5). We therefore compared the cases present in the literature with one that happened in our center in January 2018 (Box 1), evaluating the main characteristics. Overall, 39 patients with renal adrenal fusion or adrenal ectopia were considered.
The main aspects examined in this review of the literature were the clinical presentation, the type of adrenal anomaly found, the location of this anomaly, the definitive anatomopathological report and the presence of immunehistotypic markers (Table 1).

\section{Type of adrenal anomalies}

"Adrenal rest" were present in 29 patients, "adrenal renal fusion" was present in 9 patients (Table 1). All cases had adrenal cortex tissue, in the absence of heterotopia with regard to the medullary portion.

We found 1 case of "true heterotopia" as published by Chin 
et al. in 1994 (6). In this case, the absence of an adrenal gland on the right side and the presence of normal left gland on the preoperative CT scan suggests a true heterotopia. From our review, it emerged, that the most frequent form of adrenal heterotopia is the adrenal rest, and in alignment with these findings, our clinical case also had this form of adrenal abnormality.

\section{Clinical presentation}

In 11 patients the diagnosis was incidental, in 8 patients the mass was found after clinical investigation was performed for flank or abdominal pain, in 7 patients presented with manifestations of endocrinological disorders, and in 3 patients, it was diagnosed during imaging evaluations which were performed for arterial hypertension refractory to therapy or metabolic syndrome.

The onset of symptomatology was not reported in 9 patients derived from a retrospective case series (11).

Most of the clinical cases in the literature have been accidentally diagnosed during clinical investigations for abdominal or lower back pain, high blood pressure, or during diagnostic routines for concomitant neoplasms. Seven cases showed endocrinological disorders such as Cushing syndrome, primary hyperaldosteronism or were present in the context of congenital anomalies such as BeckwithWiedemann syndrome $(9,16,20,23,24,26,30,33,35)$. Abdominal pain may be due to an ureteropelvic obstruction due to the mass effect of the neoplasm, as in the case presented by Goren et al. (14) and Lee et al. (31).

In another five cases the abdominal pain was not motivated by the size or the location of the adrenal abnormalities $(15,20,22,29,32)$.

Cushing syndrome was the most frequent clinical presentation when a secreting ectopic adrenal adenoma was reported $(9,16,23,26,30,35)$. The clinical presentation included moon facies, hirsutism, easy bruising and weakness, polydipsia and polyuria. Elevated blood pressure refractory to anti-hypertensive drugs was also present. In these patients, surgical removal of the adrenal adenoma led to a regression of symptoms except for the case published by Suverijns et al. in which the pressure remained high $(10,17,28)$.

In one case described by Cardinalli et al. in 2012 the adrenal rest was diagnosed during complementary radiological studies in a patient with Beckwith-Wiedemann Syndrome (BWS) (24).

BWS is a growth disorder characterized by macrosomia, macroglossia, organomegaly, abnormalities of the ears, an increased risk for development of embryonal tumors and disorders of the adrenal gland. In this particular case the presence of ectopic adrenal tissue at the level of left renal hilum was associated with a myelolipoma but the authors concluded that a clear relationship between BWS, adrenal adenoma and myelolipoma is unclear (24).

In our case, the diagnosis was incidental during routine investigation. In fact, the patient did not report abdominal pain, and did not manifest any endocrinological abnormalities or elevated blood pressure.

\section{Location and CT-presentation}

$\mathrm{CT}$ is considered the gold standard for the characterization of renal cancers. Multiphase CT has a sensitivity of
$90 \%$ to $99 \%$ and a specificity of $99 \%$ to $100 \%$. In our review, MRI was the method of choice for the study of renal mass only in two cases $(9,27)$. However, small kidney masses can exhibit similar behaviors making the differential diagnosis process difficult.

Renal adrenal fusion as described by Rokitansky is due to the absence of adipose tissue that normally separates the adrenal gland and the upper pole of the kidney. In our review we identified 9 cases of renal adrenal fusion all located at the upper renal pole (Table 2).

Among the 29 patients with adrenal rest, 17 had a localization at the kidney, 7 at the level of the renal hilum and 5 at the level of the retroperitoneum in close proximity to the renal peduncle (Table 2).

In patients with localization at the kidney, the lesion most commonly occurred in the upper pole, while only 3 patients, including our case, had a lesion located in the middle third of the kidney $(11,31)$.

In this subgroup of patients, the differential diagnosis included clear cell renal cell carcinoma (ccRCC), angiomyolipoma (AML), oncocytoma, papillary renal cell carcinoma (pRCC) and cystic RCC. In the remaining case reports with extra renal localization the differential diagnosis included lymph node metastases and ureteral tumors (Table. 2).

Only 3 case reports present in our review reported the Hounsfield Units (HU) of the neoplasms. Fan et al. found that the lesion had a HU of 9-10. In this case, given the radiographic characteristics of the lesion, the differential diagnosis included a cystic renal neoplasm (18). Mahadevia et al. found a variation in $\mathrm{HU}$ depending on the phase of the study from -19 to +58 and +22 .

In this case the differential diagnosis was between AML and RCC (22). Liu et al., reported a change in HU from 35 to 161. In this case the differential diagnosis included AML, Oncocytoma, Paraganglioma and RCC (33). In our case, the neoplasm showed a behavior similar to that described by Mahadevia. In fact, the neoplasm had different HU $-5,+90$ and +60 according to the different phases of the CT study. Also, in our case, the main differential diagnoses were AML and RCC.

\section{Anatomopathological report}

More frequently these adrenal changes have a benign behavior and can be classified as functioning or nonfunctioning adenomas. However, in some cases, they may experience neoplastic degeneration as published by Yokoyama et al. and Lee et al. $(25,31)$.

Godin et al. in 2014 published the first case of adrenocortical heterotopic oncocytoma of the kidney. As reported, the additional cases present in the literature had extrarenal locations being localized at the spinal or retroperitoneum level (27). Our case, according with the literature is one with a non-functioning adrenocortical adenoma (Box 1 Table 1).

Additionally, the absence or poor presence of fibrous tissue between the kidney and heterotopic tissue was commonly reported, and a contact between the adrenal tissue and the renal parenchyma is frequently described. This feature is also present in our case (Figure 2).

\section{Immune-histotypic markers}

The immunohistochemistry has a pivotal role in the final 
Figure 2.

"A-B": renal neoformation localized to the middle third of the left kidney; "C-D": adrenal glands with regular size, morphology and localization.

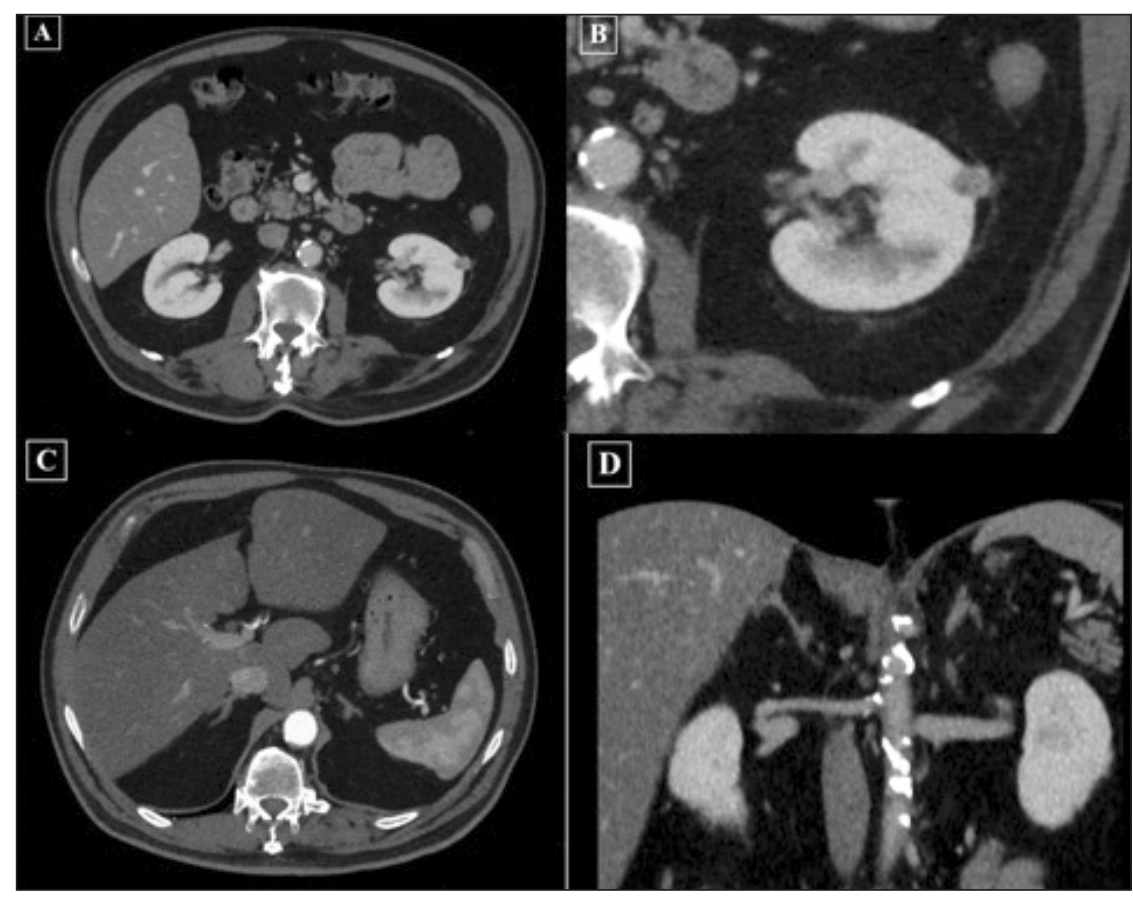

therefore, was not investigated with immunohistochemistry (Figure 2). Adrenal heterotopia is a rare condition, present in about $1 \%$ of the adult population. The main locations are celiac axis, broad ligament, spinal cord and other retroperitoneal parenchymatous organs and this is due to the embryological development of the adrenal gland.

Adrenal heterotopia is a benign and asymptomatic condition; however, it can become evident clinically when endocrinological disorders manifest, neoplastic transformation occurs, or mass effect arises.

In most cases it presents itself as an incidental finding during routine examinations performed for other causes and can mimic a solid lesion affecting parenchymatous organs, a retroperitoneal lesion compatible with a neoplasm or a metastasis if diagnosed during diagnostic investigations for other malignancies. Having a heightened clinical suspicion for these neoplasms in the setting of small renal masses will improve detection and

diagnosis. In our review, 17 studies investigated the use of immunohistochemistry in the diagnostic phase.

Chin et al. in 1994, first used immunohistochemistry to establish the steroidogenic potential of the sample under examination (6). The kidney was incubated with adrenal ectopic tissue and specific antibodies for cytochrome p 450 scc (a mitochondrial enzyme implicated in the synthesis of steroid hormones), and a high response to the adrenal ectopic tissue was found. Subsequently, further markers were used in the differential diagnosis. The most frequently positive markers were inhibin, vimentin, melan-A, synaptophysin and anti-p450 scc (Table 1).

Our case report did not pose a diagnostic doubt and

\section{Figure 3.}

Histopathological findings of an ectopic adrenal gland. Normal kidney parenchyma with glomeruli and tubules can be seen (BLUE SQUARE).

The right side is occupied by normal tissue of the adrenal gland, where cells belonging to the fasciculata and the reticularis can be spotted (YELLOW STAR).

While the orthotopic adrenal gland is embedded and separated by the renal parenchyma by a fibrous capsule most of the time, in this case the glandular tissue appears to be embedded directly in the renal parenchyma, since it is directly adjacent to it without any visible capsule or connective tissue.

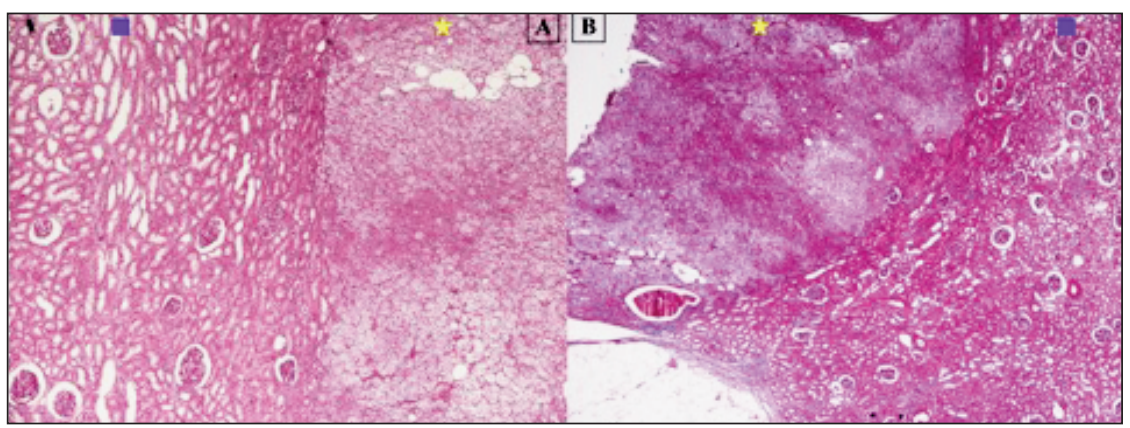

allow more appropriate therapeutic planning with important clinical implications. In this review, we considered the clinical characteristics of a subgroup of adrenal heterotopias such as those located at the renal, perirenal and retroperitoneal level in order to identify the main differences that can guide clinicians towards to a correct preoperative diagnosis. As we reported, clinical presentation can be very varied. In most cases, it is silent and diagnosed during routine exams. In other cases, if the adenoma is secreting hormones, it manifests itself with endocrinological disorders, hypertension refractory to medical therapy or abdominal pain.

The most frequently occurring location of this lesion is at the level of the upper pole of the kidney with a typical morphology of solid lesion with fat content, and a hyper-vascularized pattern which includes differential diagnoses of AML or ccRCC (Table 2).

In these, an attenuation of $-10 \mathrm{HU}$ or less is similar to AML. A strong contrast during CMP with HU values greater than 100 with subsequent wash-out during the nephrogenic phase is similar to ccRCC. Also, pRCC has a more subtle enhancement pattern than ccRCC, further complicating the list of differentials (36). Finally, it can also present itself as a complex cyst as published by Fan et al. and, in this case the differential diagnosis is with cystic RCC (18).

More frequently the anatomopathological report is a benign adenoma, however an adrenocortical neoplasm or other histological subtypes may be 
present sporadically as published by Godin et al. in 2014 (27). In many of the cases present in this review, immunohistochemical markers were used, in fact the histological structure was not always correctly reported. This is especially true for cases of adrenocortical carcinoma and rarer histological subtypes.

The characteristics that our clinical case carried, correspond to clinical characteristics presented in the literature. The diagnosis was incidental during routine investigation, no painful or endocrinological symptoms were present. When the definitive anatomopathological report showed a well differentiated adrenal adenoma, further immunohistochemical investigations could have been avoided. The main feature that distinguishes our clinical case is the localization at the level of the middle third of the kidney on the lateral margin which is present only in two other clinical cases $(11,31)$.

In our case, we proposed active surveillance, given the size of the mass, however the patient chose surgery to relieve the anxiety of carrying a cancer diagnosis. We had not proposed a renal biopsy and the EAU guidelines do not recommend a renal biopsy on a mass with contrast enhancement, given the high diagnostic accuracy of radiographic imaging. Furthermore, biopsy is not currently a requirement for initiating active surveillance (3). In a recent systematic review, Mir et al. found that less than $30 \%$ of patients included in retrospective active surveillance studies had a confirmatory biopsy (4). The diagnostic accuracy and safety of the method, previously controversial, are currently supported by a recent metaanalysis (37).

In the absence of a definitive histology, active surveillance is based on initial dimensions and on its growth estimated as linear grow rate $(\mathrm{cm} / \mathrm{yr})$ but unfortunately growth is not an indicative parameter of the biology of a lesion, as even benign lesions can have a volumetric increase (4). On the contrary, a retrospective study done at Columbia University showed that low growth rate lesions do not progress to metastatic disease (38).

Although it is a rare condition, adrenal heterotopia at the renal level presents itself as a contrast-enhancing neoplasm and therefore worthy of biopsy to avoid unnecessary surgery.

Certainly, in the presence of a lesion suspected of renal neoplasia, it is difficult to include within the differential diagnosis a condition with such a low incidence, but, the presence of endocrinological disorders, hypertension refractory to medical therapy can guide the differential diagnosis process. Other symptoms such as abdominal pain, appear to be of lesser help in the diagnostic phase as it is linked to the localization of the neoplasm and to its size and not to a peculiar characteristic of the adrenal anomaly. The main location of the adrenal fusion is at the level of the superior pole, and adrenal rest can also be present in the retroperitoneum adjacenct to the renal pelvis. However, in some cases, such as ours, the adrenal ecotopia can also be localized at the level of the lateral margin of the kidney.

This systematic review has intrinsic limitations such as the fact that it examines case series and case reports and the non-homogeneity of the cases taken into consideration. However, it underlines the main characteristics of the types of adrenal ectopic tissue in the kidney. The astute clinician should be cognizant of this condition in the evaluation of small renal masses due to its benign behavior, and its differentiation by renal cancer could require a renal biopsy because active surveillance is indicated in these patients.

\section{Conclusions}

The increase in the incidence of small renal masses due to the diffusion of radiological imaging has led to a better understanding of the behavior of these neoformations. Ectopic adrenal tissue in the kidney is a rare event with specific clinical characteristics which can clinically mimic a renal neoplasia and needs to be known in order to arrive at a correct diagnosis and carry out appropriate treatment management.

\section{REFERENCES}

1. Ferlay J, Colombet M, Soerjomataram I, et al. Cancer incidence and mortality patterns in Europe: Estimates for 40 countries and 25 major cancers in 2018. Eur J Cancer. 2018; 103:356-387.

2. Akdogan B, Gudeloglu A, Inci K, et al. Prevalence and predictors of benign lesions in renal masses smaller than $7 \mathrm{~cm}$ presumed to be renal cell carcinoma. Clin Genitourin Cancer. 2012; 10:121-5.

3. Ljungberg B, Albiges L, Abu-Ghanem Y, et al. European Association of Urology Guidelines on Renal Cell Carcinoma: The 2019 Update. Eur Urol. 2019; 75:799-810.

4. Mir MC, Capitanio U, Bertolo R, et al. Young Academic Urologists Kidney Cancer working group of the European Urological Association. Role of active surveillance for localized small renal masses. Eur Urol Oncol. 2018; 1:177-187.

5. Brčic I, Leniček T, Ulamec $M$, et al. Intrarenal ectopic adrenal tissue associated with renal angiomyolipoma. Pathol Int. 2011; 61:778-80.

6. Chin L, Brody RI, Morales P, Black VH. Immunocytochemical characterization of intrarenal adrenal tissue. Urology. 1994; 44:429-32.

7. von Rokitansky, KF. A manual of pathological anatomy. Vol. 3. 1855: Blanchard \& Lea.

8. Bamford R, Bretherton J, Rosenfelder N, Bell J. Bilateral adrenalrenal fusion: A radiological diagnosis. BJR Case Rep. 2018; 5:20180108.

9. Wang XL, Dou JT, Gao JP, et al. Laparoscope resection of ectopic corticosteroid-secreting adrenal adenoma. Neuro Endocrinol Lett. 2012; 33:265-7.

10. Zhang J, Liu B, Song N, et al. An ectopic adreocortical adenoma of the renal sinus: a case report and literature review. BMC Urol. 2016; 16:3.

11. Ye H, Yoon GS, Epstein JI. Intrarenal ectopic adrenal tissue and renal-adrenal fusion: a report of nine cases. Mod Pathol. 2009; 22:175-81.

12. Moher D, Liberati A, Tetzlaff J, et al. Preferred reporting items for systematic reviews and meta-analyses: the PRISMA statement. PLoS med. 2009; 6:e1000097.

13. Szumera A, Okoń K, Dobrowolska B, Dobrowolski Z. Adrenal rest presenting as a renal cyst. A case report. Pol J Pathol. 2003; $54: 273-6$ 
14. Goren E, Engelberg IS, Eidelman A. Adrenal rest carcinoma in hilum of kidney. Urology. 1991; 38:187-90.

15. Colberg JW, Cai X, Humphrey PA. Unilateral adrenal heterotopia with renal-adrenal fusion. J Urol. 1998; 160:116.

16. Ayala AR, Basaria S, Udelsman R, et al. Corticotropin-independent Cushing's syndrome caused by an ectopic adrenal adenoma. J Clin Endocrinol Metab. 2000; 85:2903-6.

17. Souverijns G, Peene P, Keuleers H, Vanbockrijck M. Ectopic localisation of adrenal cortex. Eur Radiol. 2000; 10:1165-8.

18. Fan F, Pietrow P, Wilson LA, et al. Adrenal pseudocyst: a unique case with adrenal renal fusion, mimicking a cystic renal mass. Ann Diagn Pathol. 2004; 8:87-90

19. Hsu TH, Kessler R. Ectopic adrenal tissue as radiographic lymphadenopathy in renal cell carcinoma. Int Urol Nephrol. 2005; 37:25-6.

20. Claahsen-van der Grinten HL, Duthoi K, Otten BJ, et al. An adrenal rest tumour in the perirenal region in a patient with congenital adrenal hyperplasia due to congenital 3beta-hydroxysteroid dehydrogenase deficiency. Eur J Endocrinol. 2008; 159:489-91

21. Linder B, Hong Y, Jarrett T. Intra-renal adrenal adenoma: a compelling addition to the differential diagnosis of renal mass. Int $J$ Urol. 2009; 16:912-4.

22. Mahadevia S, Rozenblit A, Milikow D, Marinovich A. Renaladrenal fusion: instance of an adrenal adenoma mimicking a solid renal mass at CT--case report. Radiology. 2009; 251:808-12.

23. Louiset E, Gobet F, Libé R, et al. ACTH-independent Cushing's syndrome with bilateral micronodular adrenal hyperplasia and ectopic adrenocortical adenoma. J Clin Endocrinol Metab. 2010; 95:18-24.

24. Cardinalli IA, de Oliveira-Filho AG, Mastellaro MJ, et al. A unique case of synchronous functional adrenocortical adenoma and myelolipoma within the ectopic adrenal cortex in a child with BeckwithWiedemann syndrome. Pathol Res Pract. 2012; 208:189-94

25. Yokoyama H, Adachi T, Tsubouchi K, et al. Non-functioning adrenocortical carcinoma arising in an adrenal rest: immunohistochemical study of an adult patient. Tohoku J Exp Med. 2013; 229:267-70

26. Tong A, Jia A, Yan S, et al. Ectopic cortisol-producing adrenocortical adenoma in the renal hilum: histopathological features and steroidogenic enzyme profile. Int J Clin Exp Pathol. 2014; 7:4415-21

27. Godin K, Bang N, Tolkach Y. Case report: Heterotopic intrarenally located adrenocortical oncocytoma. F1000Res. 2014; 3:73.

28. Boll G, Rattan R, Yilmaz O, Tarnoff ME. Intraoperative identification of adrenal-renal fusion. J Minim Access Surg. 2015; 11:205-6.

29. St Clair S, Machnicki S, Yurovitsky A. Adrenal renal fusion confusion: a case report of an adrenal cortical adenoma with adrenalrenal fusion. Clin Imaging. 2015; 39:695-8

30. Zhao Y, Guo H, Zhao Y, Shi B. Secreting ectopic adrenal adenoma: A rare condition to be aware of. Ann Endocrinol (Paris). 2018, 79:75-81.

31. Lee JH, Choi YD, Cho NH. An Intrarenal adrenocortical carcinoma arising in an adrenal rest. J Pathol Transl Med. 2018; 52:416-419.

32. Baydar D, Aydin O. Confusing cases: clear cell but not renal cell lesions in kidney. Pathol Int. 2008; 58:713-7.

33. Liu Y, Jiang YF, Wang YL, et al. Ectopic adrenocortical adenoma in the renal hilum: a case report and literature review. Diagn Pathol. $2016 ; 11: 40$.
34. Sappal S, Sulek J, Smith SC, Hampton LJ. Intrarenal adrenocortical adenoma treated by robotic partial nephrectomy with adrenalectomy. J Endourol Case Rep. 2016; 2:41-3.

35. Lu D, Yu N, Ma X, et al. An ectopic adrenocortical adenoma in renal hilum presenting with Cushing's syndrome: A case report and literature review. Medicine (Baltimore). 2018; 97:e13322.

36. van Oostenbrugge TJ, Fütterer JJ, Mulders PFA. Diagnostic imaging for solid renal tumors: a pictorial review. Kidney Cancer. 2018; 2:79-93

37. Marconi L, Dabestani S, Lam TB, et al. Systematic review and meta-analysis of diagnostic accuracy of percutaneous renal tumour biopsy. Eur Urol. 2016; 69:660-673.

38. Haramis G, Mues AC, Rosales JC, et al. Natural history of renal cortical neoplasms during active surveillance with follow-up longer than 5 years. Urology. 2011; 77:787-91.

\section{Correspondence}

Davide De Marchi, MD

Federico Scarfò, MD

Giovanni Passaretti, MD

Salvatore Smelzo, $M D$

Silvia Proietti, $M D$

Lorenzo Rigatti, MD

Leonardi Rosario, MD

Guido Giusti, MD

Franco Gaboardi, MD

Department of Urology, San Raffaele Hospital, Milan (Italy)

Alessandro Tafuri, MD (Corresponding Author)

tafuri.alessandro@gmail.com

Department of Urology, University of Verona, Azienda Ospedaliera Universitaria Integrata Verona, Piazzale Stefani 1, 37126, Verona (Italy)

Guglielmo Mantica, MD

Department of Urology, University of Genova, Ospedale San Martino, Genova (Italy)

Aliasger Shakir, MD

USC Institute of Urology, Catherine and Joseph Aresty Department of Urology, Keck School of Medicine, University of Southern California (USC), Los Angeles, CA (USA)

Roberta Luciano, MD

Department of Pathology, San Raffaele Hospital, Milan (Italy)

Alessandro Antonelli, MD

Department of Urology, University of Verona, Azienda Ospedaliera Universitaria Integrata Verona, Verona (Italy)

Vincenzo Pagliarulo, MD

Urology and Andrology Unit - Azienda Ospedaliera 'Vito Fazzi', Lecce, Italy 